\title{
Contribution of FEF to Attentional Periodicity during Visual Search: A TMS Study
}

\author{
(D)Laura Dugué, ${ }^{1,2}$ Alexy-Assaf Beck, ${ }^{3}$ Philippe Marque, ${ }^{4}$ and ${ }^{\circledR}$ Rufin VanRullen ${ }^{5,6}$
}

https://doi.org/10.1523/ENEURO.0357-18.2019

\begin{abstract}
${ }^{1}$ Centre National de la Recherche Scientifique (CNRS), Unité Mixte de Recherche 8002, 75006 Paris, France, ${ }^{2}$ Université Paris Descartes, Sorbonne Paris Cité, Integrative Neuroscience and Cognition Center, 75006 Paris, France, ${ }^{3}$ Psychological Sciences Research Institute and Institute of Neuroscience, Université de Louvain, B-1348 Louvain-la-Neuve, Belgique, ${ }^{4}$ Médecine Physique et de Réadaption, 31059 Toulouse, France, ${ }^{5}$ CNRS, Unité Mixte de Recherche 5549, Faculté de Médecine de Purpan, 31052 Toulouse, France, and ${ }^{6}$ Université de Toulouse, Centre de Recherche Cerveau et Cognition, Université Paul Sabatier, 31052 Toulouse, France
\end{abstract}

\begin{abstract}
Visual search, looking for a target embedded among distractors, has long been used to study attention. Current theories postulate a two-stage process in which early visual areas perform feature extraction, whereas higherorder regions perform attentional selection. Such a model implies iterative communication between low- and high-level regions to sequentially select candidate targets in the array, focus attention on these elements, and eventually permit target recognition. This leads to two independent predictions: (1) high-level, attentional regions and (2) early visual regions should both be involved periodically during the search. Here, we used transcranial magnetic stimulation (TMS) applied over the frontal eye field (FEF) in humans, known to be involved in attentional selection, at various delays while observers performed a difficult, attentional search task. We observed a periodic pattern of interference at $\sim 6 \mathrm{~Hz}$ (theta) suggesting that the FEF is periodically involved during this difficult search task. We further compared this result with two previous studies (Dugué et al., 2011, 2015a) in which a similar TMS procedure was applied over the early visual cortex (V1) while observers performed the same task. This analysis revealed the same pattern of interference, i.e., V1 is periodically involved during this difficult search task, at the theta frequency. Past V1 evidence reappraised for this paper, together with our current FEF results, confirm both of our independent predictions, and suggest that difficult search is supported by low- and high-level regions, each involved periodically at the theta frequency.
\end{abstract}

Key words: FEF; periodicity; theta; TMS; V1; visual search

\section{Significance Statement}

Attention models postulate a two-stage process during visual search in which early visual regions perform feature extraction, while higher-order regions perform attentional selection, these two levels iteratively (periodically) communicating until target recognition. Using TMS, we tested whether there is a causal link between these brain regions and attentional search performance. Similar to past V1 evidence reappraised in this study, we showed that difficult attention search is supported in the FEF by periodic processing at the theta frequency $(\sim 6 \mathrm{~Hz})$. Together, these two findings support the idea that difficult search tasks are processed by a hierarchical system involving low- and high-level regions, each involved periodically, and allowing successful attentional exploration. Nonetheless, their potential interactions remain to be demonstrated. 


\section{Introduction}

Covert attention selectively enhances visual processing at the attended location in the absence of eye movement. In the past decade, researchers studying the temporal dynamics of visual information processing have proposed that attention samples visual information periodically at low frequencies, theta $(5-7 \mathrm{~Hz}$; VanRullen et al., 2007; Busch and VanRullen, 2010; Landau and Fries, 2012; Fiebelkorn et al., 2013, 2018; VanRullen, 2013; Song et al., 2014; Huang et al., 2015; Landau et al., 2015; Dugué et al., 2015a,b, 2016, 2017; Helfrich et al., 2018) and alpha (8-12 Hz; Dugué and VanRullen, 2014; van Diepen et al., 2016; for review, see VanRullen, 2016). Critically, it has been proposed that the distinction between theta and alpha periodicity comes from the spatial exploration of the visual scene by attention (Dugué and VanRullen, 2017). In other words, when attention is not critical for the task, visual information is processed at the alpha frequency, whereas when attention explores the visual space (e.g., in cueing or visual search tasks), then visual information is processed at the theta frequency.

Visual search tasks, in which observers look for a target embedded among distractors, have long been used to study attentional deployment (for review, see: Eckstein, 2011; Nakayama and Martini, 2011). In search tasks known as difficult, authors have proposed a hierarchical processing stream (Palmer et al., 1993; Treisman, 1998; Itti and Koch, 2001; Deco et al., 2002). An early stage, presumably supported by early visual areas, would decompose the visual scene in given features (e.g., color, orientation, etc.). A high-level stage would then perform attentional selection, i.e., a priority map would select the spatial location of a candidate target to focus attentional resources on. The facilitation of target processing would then occur by sending feedback connections (Juan and Walsh, 2003; Saalmann et al., 2007; Dugué et al., 2011, 2015a) to the corresponding retinotopic region (Motter, 1994; Mehta et al., 2000; Schroeder et al., 2001; Kastner and Pinsk, 2004; Bressler et al., 2008). In such a model, this selection would iterate until target recognition, making two independent predictions: (1) high-level, attentional regions and (2) early visual regions both entail periodic processing during difficult, attentional search (Dugué et al., 2015a; Dugué and VanRullen, 2017). We here directly tested the first of these two predictions for the right

Received September 11, 2018; accepted February 22, 2019; First published June 7, 2019.

The authors declare no competing financial interests.

Author contributions: L.D. and R.V. designed research; L.D., A.-A.B., and P.M. performed research; L.D. and R.V. analyzed data; L.D. and R.V. wrote the paper.

This work was supported by an ERC Consolidator Grant P-CYCLES 614244 to R.V., and an NRJ grant to R.V. and L.D. We thank Samuel Planton for his help with the FEF localization based on structural MRI.

Correspondence should be addressed to Laura Dugué at Laura.dugue@parisdescartes.fr.

https://doi.org/10.1523/ENEURO.0357-18.2019

Copyright @ 2019 Dugué et al.

This is an open-access article distributed under the terms of the Creative Commons Attribution 4.0 International license, which permits unrestricted use, distribution and reproduction in any medium provided that the original work is properly attributed. frontal eye field (FEF), and reappraised previously published data from visual cortex (V1) to emphasize and recontextualize in a new framework the second prediction.

We used transcranial magnetic stimulation (TMS) applied over the FEF, known to be involved in attentional selection (Kastner et al., 1999; Corbetta and Shulman, 2002), at various delays while observers performed a difficult, attentional search task. We compared the results to two previously published studies (Dugué et al., 2011, 2015a) using the same difficult search task (finding the letter $\mathrm{T}$ among $\mathrm{L}$ letters) while observers were stimulated over the occipital pole (V1/V2) using a similar TMS protocol (for a comprehensive review, see Table 1). We found that, as observed for previous $V 1$ results, the FEF is periodically involved during the difficult search task, at the theta frequency $(\sim 6 \mathrm{~Hz})$.

\section{Materials and Methods}

\section{Participants}

Twenty-three participants (7 women), aged 24-38 years old, were recruited. Two did not complete the experiment because of discomfort due to the stimulation. All participants gave written informed consent before the experiment. Standard exclusion criteria for TMS were applied. The study was approved by the local ethics committee Sud-Ouest et Outre-Mer I (protocol 2009A01087-50) and followed the Code of Ethics of the World Medical Association (Declaration of Helsinki), and international guidelines and safety rules for TMS experiments (Rossi et al., 2009).

\section{Stimulus procedure}

Participants were placed $57 \mathrm{~cm}$ from the screen $(36.5 \times$ $27^{\circ}$ of visual angle) in a dark room. Their head was maintained by a chinrest and headrest. They performed 26 blocks of 72 trials each. One block was used for practice. One block allowed the determination of the stimulus onset asynchrony (SOA) to reach $\sim 70 \%$ correct, using a staircase procedure. Then, 24 blocks corresponded to the main experiment: 4 blocks with no TMS, 10 blocks with TMS applied over the FEF, and 10 blocks applied over the Vertex (control; see TMS procedure).

Participants performed a difficult visual search (Fig. 1; same procedure as by Dugué et al., 2011, 2015a): report the presence or absence of a target letter $\mathrm{T}$, among distractor letters Ls $\left(1.5 \times 1.5^{\circ}\right)$. On each trial, four stimuli were presented on the left hemifield at constant eccentricity $\left(6^{\circ}\right)$ : either four L's (target absent trials) or three L's and one $\mathrm{T}$ (target present trials), randomly presented in four orientations $\left(0,90,180\right.$, or $270^{\circ}$ from upright). Stimuli were always presented in the left visual field. Behavioral responses were evaluated as per $d^{\prime}$, hit rates (correct responses when target present), false-alarm rates (incorrect responses when target absent) and criterion. Participants were asked to respond accurately, and with no time pressure, by pressing a key on the keyboard.

The SOA, i.e., the delay between search array onset and mask onset, was predefined for each observer to achieve $\sim 70 \%$ correct $(85 \pm 8 \mathrm{~ms})$. The total trial duration 
Table 1. TMS studies investigating the role of attention during difficult, visual search tasks

\begin{tabular}{|c|c|c|c|c|c|c|c|}
\hline \multicolumn{8}{|c|}{ Stimulation parameters } \\
\hline Study & $\begin{array}{l}\text { Behavioral } \\
\text { manipulation }\end{array}$ & Test region & Control & Type of stimulation & Stimulation intensity & $n$ & Conclusions \\
\hline Ashbridge (1997) & $\begin{array}{l}\text { Feature: color } \\
\text { Conjunction: } \\
\text { color-orientation }\end{array}$ & $\mathrm{R}-\mathrm{PC}$ & No-TMS & $\begin{array}{l}\text { Single-pulse at } 11 \text { possible } \\
\text { delays (from } 0 \text { to } 200 \mathrm{~ms} \text { ) }\end{array}$ & $80 \% \mathrm{MSI}$ & 5 & $\begin{array}{l}\text { R-PC involved in conjunction } \\
\text { but not feature tasks }\end{array}$ \\
\hline Walsh et al. (1998) & $\begin{array}{l}\text { Conjunction: } \\
\text { color-orientation }\end{array}$ & $\mathrm{R}-\mathrm{PC}$ & No-TMS & $\begin{array}{l}\text { Single-pulse at } 11 \text { possible delays } \\
\text { (from } 0 \text { to } 200 \mathrm{~ms} \text { ) }\end{array}$ & $80 \% \mathrm{MSI}$ & 3 & $\begin{array}{l}\text { R-PC involved in novel but } \\
\text { not learned conjunction } \\
\text { tasks }\end{array}$ \\
\hline Juan and Walsh (2003) & $\begin{array}{l}\text { Feature: color } \\
\text { Conjunction: } \\
\text { color-orientation }\end{array}$ & V1/N2 & No-TMS & $\begin{array}{l}10 \mathrm{~Hz} \text { for } 500 \mathrm{~ms} \text { and } \\
\text { Double-pulse ( } 40 \text { or } 100 \mathrm{~ms} \\
\text { interval) at } 6 \\
\text { possible delays }\end{array}$ & $65 \% \mathrm{MSI}$ & $\begin{array}{l}8,6 \\
\& 6\end{array}$ & $\begin{array}{l}\text { V1 involved at late delays } \\
\text { (feedback) during conjunction } \\
\text { but not feature tasks }\end{array}$ \\
\hline Muggleton et al. (2003) & $\begin{array}{l}\text { Feature: color } \\
\text { Conjunction: } \\
\text { color-orientation }\end{array}$ & $\begin{array}{l}\text { R-FEF } \\
\text { L-FEF }\end{array}$ & $\begin{array}{l}\text { Vertex } \\
\text { V5 }\end{array}$ & $10 \mathrm{~Hz}$ for $500 \mathrm{~ms}$ & $65 \% \mathrm{MSI}$ & 5 & $\begin{array}{l}\text { FEF is involved in visual } \\
\text { selection, in the absence } \\
\text { of saccade }\end{array}$ \\
\hline Ellison et al. (2004) & $\begin{array}{l}\text { Feature: orientation } \\
\text { Conjunction: } \\
\text { color-orientation }\end{array}$ & $\begin{array}{l}\text { R-PPC } \\
\text { R-STG }\end{array}$ & $\begin{array}{l}\text { SHAM on R-PPC or } \\
\text { R-STG }\end{array}$ & $\begin{array}{l}\text { R-PPC: } 10 \mathrm{~Hz} \text { for } 500 \mathrm{~ms} \\
\text { R-STG: } 4 \mathrm{~Hz} \text { for } 500 \mathrm{~ms}\end{array}$ & $65 \% \mathrm{MSI}$ & 5 & $\begin{array}{l}\text { R-PPC involved in conjunction } \\
\text { and R-STG in feature }\end{array}$ \\
\hline O'Shea et al. (2004) & $\begin{array}{l}\text { Conjunction: } \\
\text { color-orientation }\end{array}$ & R-FEF & $\begin{array}{l}\text { Vertex } \\
\text { V5 }\end{array}$ & $\begin{array}{l}\text { Double-pulse ( } 40 \mathrm{~ms} \text { interval) at } \\
5 \text { possible delays } \\
\text { (from } 0 \text { to } 120 \mathrm{~ms} \text { ), } \\
40 \mathrm{~ms} \text { before mask onset }\end{array}$ & $\begin{array}{l}\text { FEF \& Vertex: } 65 \% \mathrm{MSI} \\
\text { V5: } 110 \% \text { phosphene } \\
\text { threshold }\end{array}$ & 12 & $\begin{array}{l}\text { FEF is involved in visual } \\
\text { discrimination, in the absence } \\
\text { of saccade }\end{array}$ \\
\hline Fuggetta et al. (2006) & $\begin{array}{l}\text { Conjunction: } \\
\text { color-orientation }\end{array}$ & R-PPC & Vertex & $\begin{array}{l}\text { Single-pulse } 100 \mathrm{~ms} \text { after } \\
\text { stimulus onset }\end{array}$ & $85 \% \mathrm{MSI}$ on average & 7 & $\begin{array}{l}\text { R-PPC involved in conjunction } \\
\text { task }\end{array}$ \\
\hline Ellison et al. (2007) & $\begin{array}{l}\text { Conjunction: } \\
\text { color-orientation and } \\
\text { motion-orientation }\end{array}$ & $\begin{array}{l}\text { R-PPC } \\
\text { R-V5 }\end{array}$ & $\begin{array}{l}\text { SHAM on R-PPC or } \\
\text { R-V5 }\end{array}$ & $10 \mathrm{~Hz}$ for $500 \mathrm{~ms}$ & $65 \% \mathrm{MSI}$ & 7 & $\begin{array}{l}\text { R-PPC involved in color-orientation } \\
\text { R-V5 in motion-orientation }\end{array}$ \\
\hline Kalla et al. (2008) & $\begin{array}{l}\text { Conjunction: } \\
\text { color-orientation }\end{array}$ & $\begin{array}{l}\text { R-FEF } \\
\text { R-PPC }\end{array}$ & No-TMS & $\begin{array}{l}\text { Double-pulse ( } 40 \mathrm{~ms} \text { interval) at } \\
5 \text { possible delays } \\
\text { (from } 0 \text { to } 200 \mathrm{~ms} \text { ) }\end{array}$ & $60 \% \mathrm{MSI}$ & 9 & $\begin{array}{l}\text { R-FEF involved earlier than } \\
\text { R-PPC in conjunction } \\
\text { tasks }\end{array}$ \\
\hline Muggleton et al. (2008) & $\begin{array}{l}\text { Feature: color } \\
\text { Conjunction: } \\
\text { color-orientation }\end{array}$ & $\begin{array}{l}\text { R-AG } \\
\text { L-AG }\end{array}$ & $\begin{array}{l}\text { Vertex } \\
\text { No-TMS }\end{array}$ & $10 \mathrm{~Hz}$ for $500 \mathrm{~ms}$ & $65 \% \mathrm{MSI}$ & 8 & $\begin{array}{l}\text { R-AG but not L-AG involved in } \\
\text { conjunction but not } \\
\text { feature tasks }\end{array}$ \\
\hline Schindler et al. (2008) & $\begin{array}{l}\text { Feature: orientation } \\
\text { Conjunction: } \\
\text { color-orientation }\end{array}$ & $\begin{array}{l}\text { R-PPC } \\
\text { R-STG }\end{array}$ & $\begin{array}{l}\text { SHAM on R-PPC or } \\
\text { R-STG }\end{array}$ & $\begin{array}{l}\text { R-PPC: } 10 \mathrm{~Hz} \text { for } 500 \mathrm{~ms} \\
\text { R-STG: } 4 \mathrm{~Hz} \text { for } 500 \mathrm{~ms}\end{array}$ & $65 \% \mathrm{MSI}$ & 5 & $\begin{array}{l}\text { R-STG processes the left part of } \\
\text { the search array presented } \\
\text { contralateral } \\
\text { R-PPC involved for left } \\
\text { visual field when } \\
\text { full-fields array }\end{array}$ \\
\hline Kalla et al. (2009) & $\begin{array}{l}\text { Feature: color } \\
\text { Conjunction: } \\
\text { color-orientation }\end{array}$ & DLPFC & $\begin{array}{l}\text { Vertex } \\
\text { V5 }\end{array}$ & TBS: $50 \mathrm{~Hz}$ bursts at $5 \mathrm{~Hz}$ & $40 \% \mathrm{MSI}$ & 12 & $\begin{array}{l}\text { DLPCF involved in conjunction } \\
\text { but not feature tasks }\end{array}$ \\
\hline Dugué et al. (2011) & $\begin{array}{l}\text { Conjunction: } \\
L \text { vs } T \text { and } L \text { vs }+\end{array}$ & V1/N2 & $\begin{array}{l}\text { Stimulus at non- } \\
\text { retinotopic } \\
\text { location }\end{array}$ & $\begin{array}{l}\text { Double-pulse }(25 \mathrm{~ms} \text { interval) } \\
\text { at } 8 \text { possible delays } \\
\text { (from } 100 \text { to } 450 \mathrm{~ms} \text { ) }\end{array}$ & $55 \% \mathrm{MSI}$ & 11 & $\begin{array}{l}\text { V1 involved at late delays } \\
\text { (feedback) during conjunction } \\
\text { but not feature tasks }\end{array}$ \\
\hline Lane et al. (2011) & $\begin{array}{l}\text { Feature: } \\
\text { shape } \\
\text { Conjunction: } \\
\text { color-orientation }\end{array}$ & R-PPC & SHAM on R-PPC & $10 \mathrm{~Hz}$ for $500 \mathrm{~ms}$ & $65 \% \mathrm{MSI}$ & 12 & $\begin{array}{l}\text { R-PPC involved in conjunction } \\
\text { and feature tasks when } \\
\text { participants have to point } \\
\text { to the target, but } \\
\text { only conjunction when } \\
\text { button press response }\end{array}$ \\
\hline Muggleton et al. (2011) & $\begin{array}{l}\text { Conjunction: } \\
\text { color-orientation }\end{array}$ & $\begin{array}{l}\text { R-FEF } \\
\text { L-PPC }\end{array}$ & No-TMS & $10 \mathrm{~Hz}$ for $500 \mathrm{~ms}$ & $60 \% \mathrm{MSI}$ & 8 & $\begin{array}{l}\text { L-PPC involved when manual } \\
\text { motor response required }\end{array}$ \\
\hline Dugué et al. (2015a) & $\begin{array}{l}\text { Conjunction: } \\
L \text { vs } T \text { and } L \text { vs }+\end{array}$ & V1/V2 & $\begin{array}{l}\text { Stimulus at non- } \\
\text { retinotopic } \\
\text { location }\end{array}$ & $\begin{array}{l}\text { Double-pulse: one at } 312.5 \mathrm{~ms} \\
\text { and one } 13 \text { possible } \\
\text { delays (from } 112.5 \\
\text { to } 437.5 \mathrm{~ms} \text { ) }\end{array}$ & $55 \% \mathrm{MSI}$ & 10 & $\begin{array}{l}\text { V1 involved periodically } \\
\text { during conjunction but } \\
\text { not feature tasks } \\
(\sim 6 \mathrm{~Hz})\end{array}$ \\
\hline Yan et al. (2016) & $\begin{array}{l}\text { Feature: } \\
\text { color } \\
\text { Conjunction: } \\
\text { orientation of triangles }\end{array}$ & $\begin{array}{l}\text { R-DLPFC } \\
\text { R-PPC }\end{array}$ & $\begin{array}{l}\text { Vertex on another } \\
\text { group of } \\
\text { participants }\end{array}$ & $\begin{array}{l}\text { Double-pulse ( } 100 \mathrm{~ms} \text { interval) } \\
200 \text { ms before search } \\
\text { array onset }\end{array}$ & $51 \% \mathrm{MSI}$ on average & 16 & $\begin{array}{l}\text { DLPFC is involved in } \\
\text { the conjunction search, } \\
\text { while the PPC is involved } \\
\text { in the feature search }\end{array}$ \\
\hline Present study & $\begin{array}{l}\text { Conjunction: } \\
\text { L vs T }\end{array}$ & R-FEF & Vertex & $\begin{array}{l}\text { Double-pulse ( } 25 \mathrm{~ms} \text { interval) at } 9 \\
\text { possible delays (from } 50 \\
\text { to } 450 \mathrm{~ms} \text { ) }\end{array}$ & $52 \% \mathrm{MSI}$ on average & 21 & $\begin{array}{l}\text { FEF involved periodically } \\
\text { during a conjunction } \\
\text { task }(\sim 6 \mathrm{~Hz})\end{array}$ \\
\hline
\end{tabular}

For each study we report the behavioral manipulation, the stimulation parameters: tested region (R, Right; L, Left; V5, MT area; PC, parietal cortex; PPC, posterior parietal cortex; AG, angular gyrus, part of the PPC; STG, superior temporal gyrus; DLPFC, dorsolateral prefrontal cortex, right hemisphere), control condition, type of stimulation (TBS, theta burst stimulation; note: otherwise mentioned, the reference is the onset of the visual stimuli) and the intensity of the stimulation (MSI, maximum output stimulation intensity of the TMS machine), the amount of participants for which data were analyzed ( $n$ ), and finally, the authors' conclusions.

(including search array and masks) was $500 \mathrm{~ms}$ for all participants. The intertrial interval was randomized between 1 and $2 \mathrm{~s}$, which, adding to the total duration of the trial, limited cumulative effects of stimulation.

\section{TMS targeting and delivery}

TMS pulses were delivered using a $70 \mathrm{~mm}$ figure-ofeight coil (biphasic stimulator, Magstim Rapid ${ }^{2}$ ). A structural T1-weighted MRI scan (3T Philips, flip angle $=8^{\circ}$, TR $=8.1 \mathrm{~ms}, \mathrm{TE}=3.7 \mathrm{~ms}, \mathrm{FOV}=240 \times 240 \mathrm{~mm}$, voxel size $=1 \mathrm{~mm}$ isotropic) was acquired for 11 participants at the imagery platform of the CerCo (Toulouse University). For these participants, the right FEF was localized on each individual MRI using averaged Talairach coordinates $x=$
$31, y=-2, z=47$ (Paus, 1996), and a 0.5 radius spherical region-of-interest (ROI; same procedure as by Chanes et al., 2012, 2013). The final MRI was uploaded into a frameless stereotaxic system and reconstructed in 3D for its use in an online TMS neuronavigation system (eXimia NBS system, Nextim).

Participants were all wearing an EEG cap to help localize the stimulated ROI on the surface. For the 11 participants whose FEF was localized using individual anatomic MRIs, the stimulation site was marked by a small sticker placed on the EEG cap. For the remaining eight participants (for whom we were unable to record a structural $\mathrm{MRI}$ ), the stimulation ROI was determined as the barycenter of the region of stimulation from the 11 previ- 


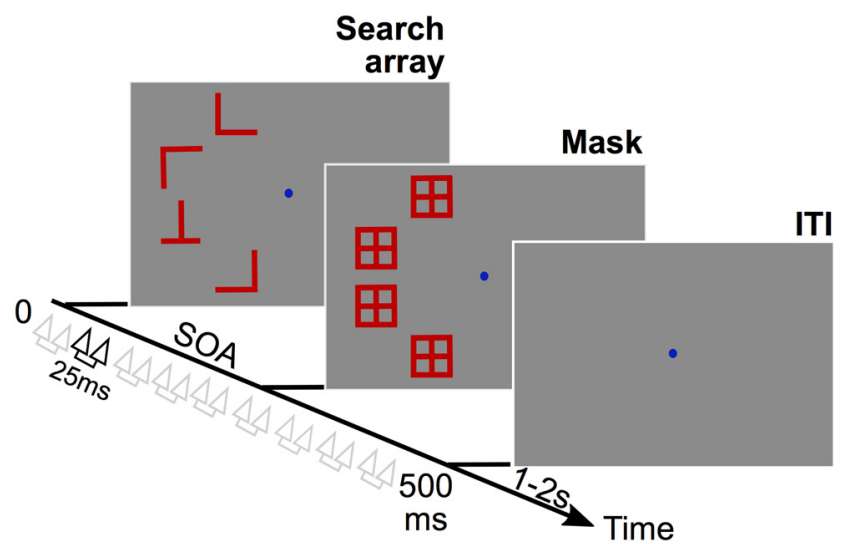

Figure 1. Experimental protocol. While participants performed a visual search (finding a T letter among L's), they were stimulated over the right-FEF or the Vertex (control) with a double-pulse of TMS (25 ms interval) applied at random delays between 50 and $450 \mathrm{~ms}$ (50 ms increments) after the search array onset.

ous participants, and also marked by a small sticker placed on the EEG cap to assist in the TMS coil positioning. The stimulation region for these participants was situated between the electrodes F2 and FC4 (MCN EEG system).

The TMS coil was placed tangentially to the skull and its handle oriented $45^{\circ}$ in a rostral-to-caudal and lateral-tomedial orientation. The stimulation intensity started at $50 \%$ of the TMS machine maximal output, and was then adjusted just below the threshold of facial and temporal muscle activation (average intensity across participants = $52 \pm 2 \%$ SEM). For comparison, Dugué et al. (2016) reported an average intensity across participants $=58 \pm$ $2 \%$ SEM of TMS machine output intensity (same TMS machine) for the phosphene threshold (perceived $50 \%$ of the time).

The Vertex was used as a stimulation control site for nonspecific TMS effects such as clicking noise and tapping sensation. This region was localized for each participant as the region under electrode $\mathrm{Cz}$ on the EEG cap (O'Shea et al., 2004). Note that this Vertex versus FEF stimulation conditions were blocked (randomization was not possible because it would have necessitated two TMS machines). Moreover, the Vertex stimulation, unlike the FEF stimulation, was not lateralized to the right hemisphere. Altogether, it is thus clear that the participants could distinguish between the different stimulation conditions. Yet, we ensured participants were unaware of the research question and of the relevance of the stimulation sites.

\section{TMS procedure}

Double-pulses of TMS (25 ms interval) were applied at random delays after search array onset to interfere with search processing ( 9 possible delays, from 50 to $450 \mathrm{~ms}$, $50 \mathrm{~ms}$ increments; Fig. 1). Note that for most of the TMS delays, the search array was no longer on the screen when TMS was applied over the FEF. TMS thus interfered with an internal representation of the array, still being processed by the visual and attentional processing stream. Additionally, the maximum delay between the stimulus offset and the last TMS pulse was kept under $400 \mathrm{~ms}$. This time interval is less than typically associated with a demand for working memory (>600 ms; Phillips, 1974).

Double-pulses were chosen (vs single-pulses) based on the results of Dugué et al. (2011). Double-pulses, although often separated by coarser intervals, are commonly used in the literature to increase the potential effect of the stimulation on performance (Juan and Walsh, 2003; O'Shea et al., 2004; Kalla et al., 2008; Dugué et al., 2011, 2015a; Yan et al., 2016). Right-FEF and Vertex stimulations were blocked. Half of the participants (randomly assigned) performed the right-FEF blocks first, whereas the other half started with the Vertex ones. Participants performed 80 trials per stimulation delay and condition, for a total of 1440 trials per session ( $2 \mathrm{~h}$ ), and 720 doublepulses per stimulated site.

\section{Reanalysis of two previously published datasets}

In the current study, we compare the effect of TMS applied at various delays over the FEF during a difficult visual search task, with the results of two previously published studies using the same search task ( $L$ vs $T$ ), while TMS was applied over the occipital pole (V1/V2).

The first dataset comes from the published study by (Dugué et al., 2011). Based on phosphene mapping, double-pulses of TMS (25 ms interval) were applied at one of various delays (8 possible delays from 100 to $450 \mathrm{~ms}$, $50 \mathrm{~ms}$ increments) to a consistent brain location in retinotopic areas (V1/V2). The search array was presented either at the location affected by the TMS pulses (phosphene region) or in the symmetric region in the opposite hemifield (retinotopically-defined control region). Thus, the stimulation was identical over the cortex but was either interfering with the stimulus, retinotopic location (phosphene condition), or not (control condition; for further methodological details, see Dugué et al., 2011).

The second dataset comes from the published study by Dugué et al. (2015a). In this study, the authors followed the same procedure as by Dugué et al. (2011). The only difference is the way the two pulses were administered. In each trial, one pulse remained fixed at a latency of 312.5 $\mathrm{ms}$ after the search array onset, based on the main effect found previously by Dugué et al. (2011). The second pulse was applied at 13 other possible delays before or after the first pulse $(112.5,137.5,162.5,187.5,212.5,237.5,262.5$, $287.5,337.5,362.5,387.5,412.5$, or $437.5 \mathrm{~ms}$ after stimulus onset; Dugué et al., 2015a). Note that, despite some methodological differences between the two V1 datasets, their reanalysis is an important test of replicability.

\section{Fourier analysis}

For all three studies, we first calculated $d^{\prime}$, criterion, hit rates and false-alarm rates (specifically, the normal inverse distribution of hit and false-alarm rates, i.e., correctly and incorrectly, respectively, reporting the presence of the target) as main dependent variables. For each of these four measures, we calculated a modulation index by subtracting the main stimulation condition and the control condition. In the current study, the modulation index was 
the difference between the right-FEF and the Vertex condition trials. In the two previously published V1 studies, the modulation index was the difference between the phosphene condition and the control condition trials (see previous section). In other words, in all three cases, negative values corresponded to a target region-specific impairment of performance by TMS.

We first combined the results from all three studies to investigate the overall TMS modulation of attentional performance during the difficult search task. Because the TMS pulses were not applied at the same delays across the three studies, we first oversampled each individual modulation time course every $12.5 \mathrm{~ms}$ using a linear interpolation. We then averaged all three datasets together (Fig. 2A,C,E,G). On this pooled dataset, we performed a fast Fourier transform (FFT; Fig. 2B,D,F,H) on padded data (using the average value) to get a $4000 \mathrm{~ms}$ segment. Note that we also did the analysis on nonpadded data and obtained comparable results. Bootstrapping assessed the significance of each frequency component: the simulations were obtained by shuffling the labels of TMS delays, following the null hypothesis that the modulation index was independent of TMS latency $(100,000$ iterations). For each of the 100,000 surrogate amplitude spectra, we selected the maximum value across frequencies (thus addressing the problem of multiple comparisons). The surrogates were then ranked in ascending order. The 95,001th value was considered as the limit of the $95 \%$ confidence interval $(\mathrm{Cl} ; p<0.05)$.

We then looked at the amplitude spectra of each single study using FFT decomposition of the hit rates modulation index only (the previous results indicating that hit rate was the most relevant of the four measures). Note that the method used here to investigate the temporal dynamics of FEF attentional processing during visual search is similar to the one used in the first V1 study (Dugué et al., 2011). To allow for a fair comparison between the two studies, it is critical to perform the same spectral analysis on both datasets, which had not been done at all by Dugué et al. (2011). On the three individual datasets, we performed an FFT on padded data (using the average value) to get a 4000 ms segment. Note that we also did the analysis on non-padded data and obtained comparable results. Here, the significance of each oscillatory component was assessed by nonparametric statistics. Monte Carlo simulations were performed under the null hypothesis that the hit rates modulation was independent of TMS latency $(100,000$ iterations). For each iteration, we recomputed the grand-averaged curve of the difference of hit rates between test and control conditions, and its amplitude spectrum. For each surrogate, we selected the maximum value across the significant frequencies obtained in the combined analysis (Fig. 2F; i.e., 5.5-6.3 Hz). We then sorted these surrogates in ascending order and calculated confidence intervals and the corresponding $p$ values (Fig. 3, left column).

Finally, for each participant in the FEF study as well as the second V1 study (Dugué et al., 2015a; we did not perform the analysis for the first V1 study, Dugué et al., 2011 , because we did not find a significant peak in fre- quency in the previous analysis), we looked at the phase distribution across participants for the significant frequency peak observed in the previous amplitude spectra (Fig. 3, right column). We computed Rayleigh statistical test to evaluate the non-uniformity of the phase across participants.

\section{Results}

To test the prediction that difficult visual search periodically involves low- and high-level regions along with iterative attentional selection, we conducted a TMS experiment in which we interfere with the FEF at various delays while observers performed a task in which they have to report the presence or absence of the letter $\mathrm{T}$ among letter L's. The modulation of $d^{\prime}$, criterion, hit rates, and false-alarm rates was calculated as the difference between the right-FEF and the Vertex (control) stimulation. These results were combined with the results of two previously published studies (Dugué et al., 2011, 2015a) using the same search task ( $L$ vs $T$ ), while TMS was applied either over the retinotopic location of the early visual cortex corresponding to the search array location, or over the symmetric (control) location (see Materials and Methods). Note that a comprehensive review of the literature on TMS studies of attention during visual search reveals that no other study had the necessary temporal sampling resolution for such an investigation (i.e., singleor double-pulses of TMS sampling a large time window at multiple delays on separate trials; Table 1). Figure $2 \mathrm{~A}$ represents the combined $d^{\prime}$ modulation across all three studies, as a function of the delays at which TMS was applied during the difficult search task. Similarly, Figure $2 \mathrm{C}$ represents the modulation of the combined criterion, Figure $2 E$ the hit rates, and Figure $2 G$ the false-alarm rates.

We further investigated the temporal dynamics of these performance modulations. An FFT applied to the combined dataset revealed a significant peak at $6.3 \mathrm{~Hz}$ for the $d^{\prime}$ modulation (Fig. 2B). A peak at $4.8 \mathrm{~Hz}$ was similarly observed for the criterion modulation (Fig. 2D). To understand further the observed periodicity in both $d^{\prime}$ and criterion, we performed the same analysis on the modulation of hit and false-alarm rates. Interestingly, we observed a significant peak frequency at $5.8 \mathrm{~Hz}$ for hit rates (Fig. 2F), but no peak in frequency for false-alarm rates (Fig. 2H). Together, these results suggest that the observed periodicity in both $d^{\prime}$ and criterion is because of the periodic modulation of hit rates around the same frequency. This is because $d^{\prime}=z$ (hit) $-z(\mathrm{fa})$, and criterion $=[z$ (hit) $+z(\mathrm{fa})] / 2$, where $z$ is the inverse normal cumulative distribution function. If sensitivity $\left(d^{\prime}\right)$ was the key variable that is periodically modulated by theta oscillations (i.e., in the absence of a criterion fluctuation), then both hits and false alarms should oscillate (with an opposite phase). Similarly, if sensory threshold (criterion) was the key variable (in the absence of $d^{\prime}$ modulations), then hits and false alarms should also both oscillate (in phase). The most likely explanation, therefore, is that oscillations directly affect hit rates, which is then indirectly (because of the two equations above) reflected in $d^{\prime}$ and criterion 
A

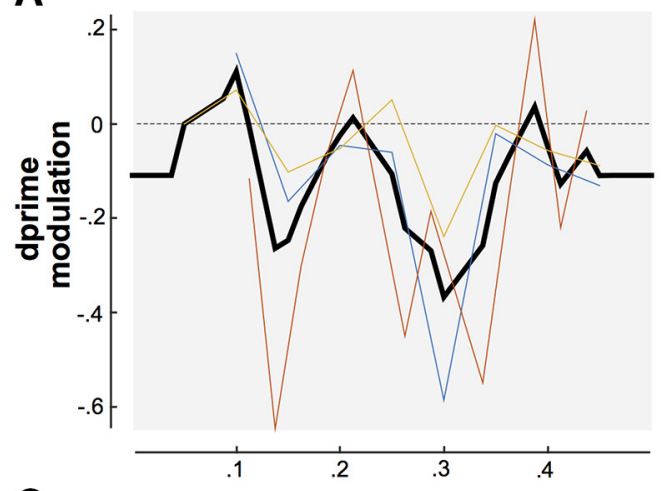

C

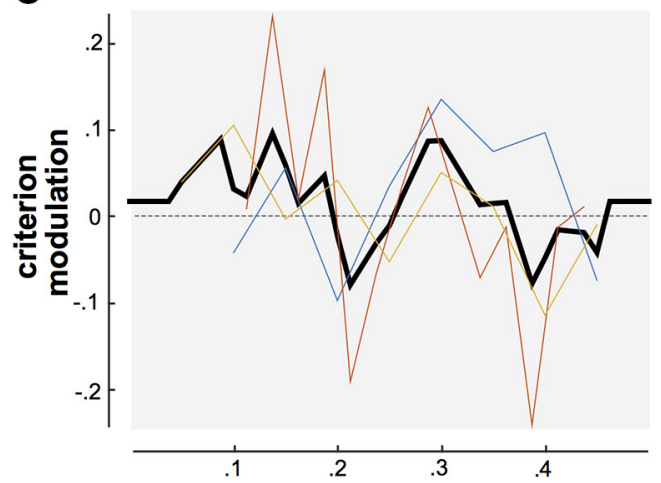

E

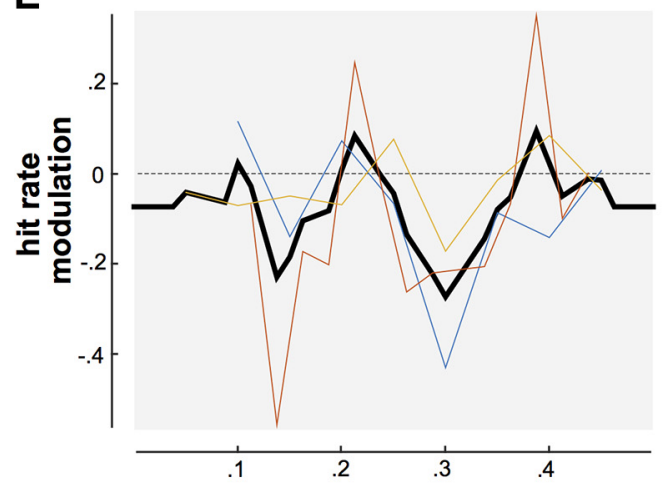

G

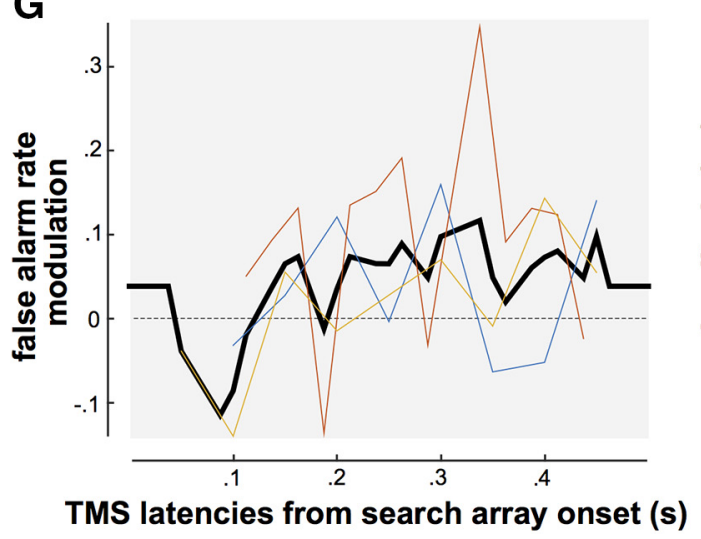

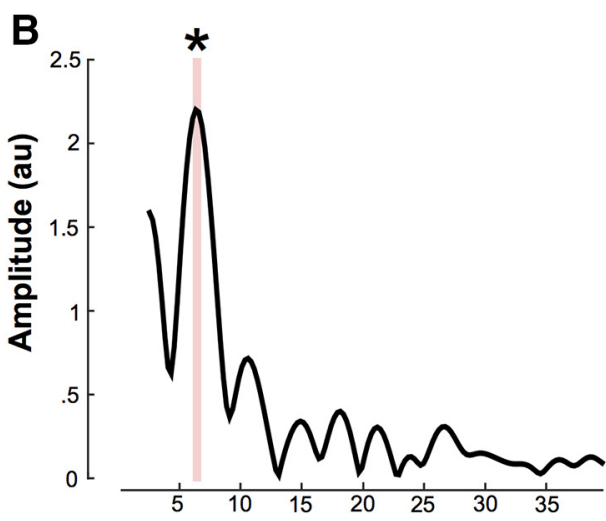

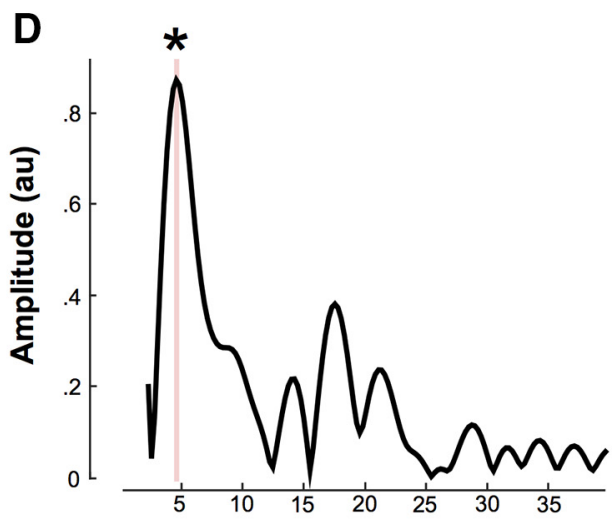

$\mathbf{F}$
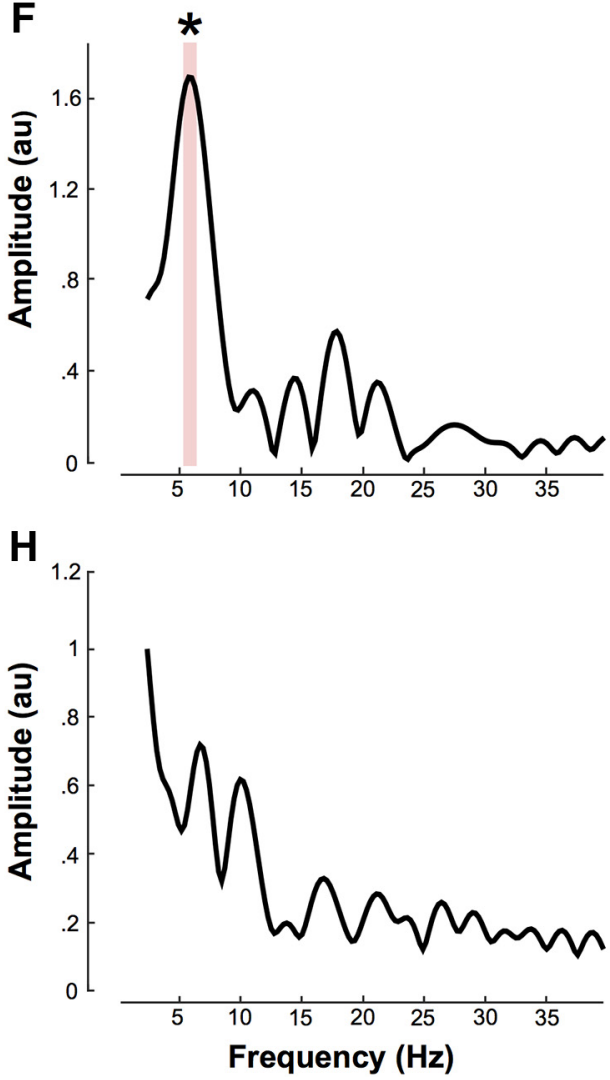

Figure 2. TMS modulates attentional search periodically. $\boldsymbol{A}, D^{\prime}$ modulations (test-control condition) are represented as a function of TMS latencies from the search array onset. The color lines represent each individual study [yellow, current FEF study; blue, first V1 study (Dugué et al., 2011); red, second V1 study (Dugué et al., 2015a)]. The black line is the average across all three studies. $\boldsymbol{B}$, Amplitude spectrum obtained by FFT decomposition of the averaged data across the three studies. The red shaded area represents the significant spectral components and the *peak at $6.3 \mathrm{~Hz}(\boldsymbol{p}<0.05) . \boldsymbol{C}, \boldsymbol{E}, \boldsymbol{G}$, represent criterion, hit rates, 
continued

and false-alarm rates modulations, respectively (same representation as in $\boldsymbol{A}$ ). $\boldsymbol{D}, \boldsymbol{F}, \boldsymbol{H}$, represent their corresponding amplitude spectra. The red shaded area represents the significant spectral components and the *peaks at $6 \mathrm{~Hz}$ and $18 \mathrm{~Hz}$ for criterion and $5.8 \mathrm{~Hz}$ for hit rates $(p<0.05)$.
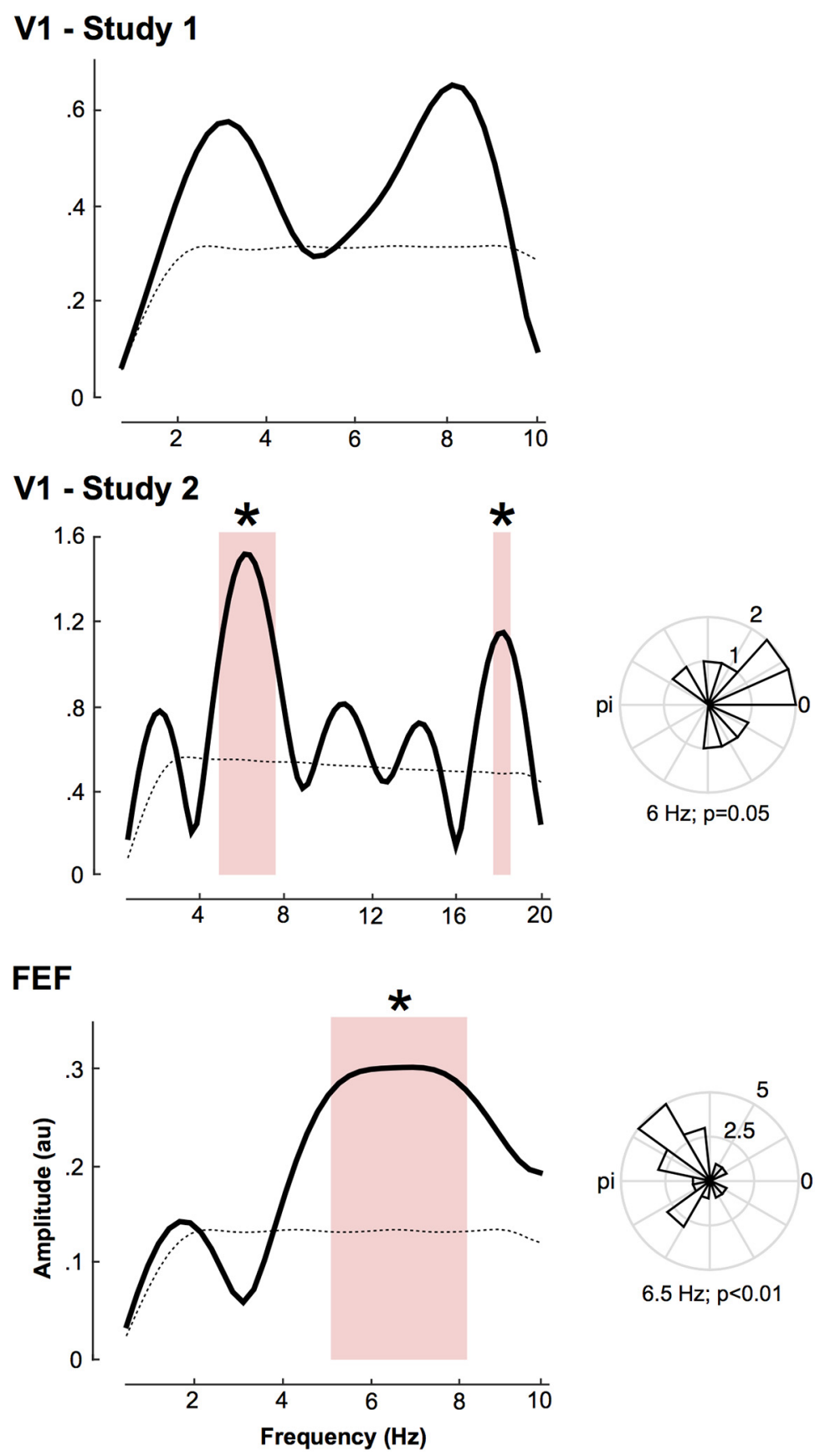

Figure 3. Attentional periodicity in V1 and FEF. For each study, the graphs in the left column represent the amplitude spectra obtained by FFT decomposition of the averaged performance (as per hit rates modulation; see Materials and Methods) across participants. Note the distinct frequency axis in the middle, because of the increased time resolution (and corresponding Nyquist frequency) in that study. The bottom, dashed black line represents the amplitude spectrum of the surrogate distribution. The red shaded area represents the significant spectral components and the *peaks at $6 \mathrm{~Hz}$ and $18 \mathrm{~Hz}$ for the second $\mathrm{V} 1$ study and $6.5 \mathrm{~Hz}$ for the FEF study $(p<$ 0.05). The right column represents the phase distribution of the peak frequency across participants. $P$ values are obtained from Rayleigh test for non-uniform distribution of circular data. 
modulations. In sum, these results suggest that TMS periodically interferes with search performance as per hit rates at the theta frequency. In the next analysis, we thus focus on the modulation of hit rates only.

Critically, to understand the origin of this overall, descriptive effect, we performed the same frequency decomposition on each individual dataset (Fig. 3). In the first V1 study (Dugué et al., 2011), we did not observe a significant peak in frequency (although the shape of the amplitude spectrum, as well as the time course of hit rates shown in Fig. $2 E$, are globally comparable with the other 2 studies). However, for both the second V1 study (Dugué et al., 2015a) and the current FEF study, we observed significant frequency peaks: $4.5-7.3$ and $17.6-18.3 \mathrm{~Hz}$ (we speculate that this second peak is because of aliasing, more susceptible at higher frequencies) for the second V1 study, and $5-8.3 \mathrm{~Hz}$ for the FEF study. This is all the more striking knowing that their respective methodologies had some differences. These methodological discrepancies are likely to explain the small frequency differences we observed between the studies (see Materials and Methods). Importantly, the theta-frequency spectral peak was present across observers, as measured by phase alignment, i.e., there was a significant concentration of the phase across observers (Fig. 3, right column; second V1 study, Rayleigh test of the $6 \mathrm{~Hz}$ component: $z=2.9, p=0.05$; FEF study, Rayleigh test of the $6.5 \mathrm{~Hz}$ component: $z=4.6, p<0.01$ ). The observed periodicity is thus not a mere effect of performance averaging across participants.

\section{Discussion}

Using TMS applied at various delays while observers performed a difficult, attentional search task, we showed that both $\mathrm{V} 1$ and the FEF are involved periodically during the search, at the theta frequency $(\sim 6 \mathrm{~Hz})$. The FEF periodicity is consistent with two recent findings. Using a cueing procedure, an electrophysiological study in monkey (Fiebelkorn et al., 2018) and an intracranial recording study in humans (Helfrich et al., 2018) both showed rhythmicity of attentional sampling at the theta frequency. Interestingly, similarly to the present study, they linked theta rhythms in frontal cortex to behavioral performance.

The reanalysis of the first and second V1 studies was to address a timely concern in the TMS literature, i.e., replicability (Biel and Friedrich, 2018; Lopez-Alonso et al., 2018). Although no significant peak frequency effect was found in the first TMS study, which may be due to various experimental factors, interestingly, a trend was observed in the theta frequency range. Further studies will be necessary to understand the discrepancy in the strength of the effect between the first and second V1 studies.

Although a direct link between the two periodicities is not demonstrated here, we may speculate these findings indirectly support the idea that visual search tasks are processed by a hierarchical system involving periodic, iterative connections between low- and high-level regions until target recognition. This hypothesis is in line with the large accumulation of evidence that attention acts via feedback to sensory areas (Motter, 1994; Mehta et al.,
2000; Schroeder et al., 2001; Kastner and Pinsk, 2004; Bressler et al., 2008; Fiebelkorn et al., 2018; Helfrich et al., 2018). An additional prediction made by such hierarchical two-way processing stream is that if both the low- and high-level regions are periodically sending information to each other, there should also be a phase lag between their respective modulations. Unfortunately, because the results were obtained from independent studies (different participants and sample sizes) and the peak frequency was not the same across the studies, we were not able to compare their phases. In the future, one could perform an experiment in which the same observers are stimulated at various delays over the FEF and V1, while performing the same difficult search task. This would allow the characterization within the same participants of the respective temporal dynamics of $\mathrm{V} 1$ and $\mathrm{FEF}$, and their interaction, during difficult visual search.

Oscillations in behavioral performance have been the topic of a large, recent body of research. Two rhythm frequencies have been reported (VanRullen, 2016), i.e., alpha $(\sim 10 \mathrm{~Hz})$ and theta $(\sim 7 \mathrm{~Hz})$. It has been suggested that while the alpha rhythm reflects an intrinsic, sensory rhythm, sampling information at a single location, theta rather reflects attentional exploration, sampling information at multiple locations (Dugué and VanRullen, 2017). This hypothesis is in line with a recent TMS experiment in humans in which attentional exploration was explicitly manipulated using a cueing paradigm (Dugué et al., 2016). By applying TMS at various delays over V1, the authors demonstrated that performance in a 2-AFC orientation discrimination task was modulated by TMS periodically at the theta frequency $(\sim 5 \mathrm{~Hz})$ only when attention had to be reallocated from a distractor to a target location. Interestingly, recent electrophysiology studies in the visual cortex of macaque monkeys showed attention-related theta rhythms in visual cortex, including areas V1 and V4 (Kienitz et al., 2018; Spyropoulos et al., 2018).

One might wonder whether the observed periodicity in all the previously described TMS studies (including the present one) is because of a true, intrinsic property of the attention system, which processes information periodically, or whether it is actually induced by the TMS. One critical piece of evidence in favor of the former is that in (Dugué et al., 2015a) the authors not only observed a periodicity in behavioral performance due to the stimulation, but also showed in independent trials without TMS (but in the same participants) that brain oscillations (as measured by EEG) at the same frequency ( $\sim 6 \mathrm{~Hz}$; theta) correlated with search performance. Consequently, oscillations likely reflect a periodicity in cortical excitability, and TMS is thus able to probe the system at different excitability states. More generally, interventional methodologies, such as TMS, have the critical advantage to go beyond mere correlational evidence and inform neural processes to establish causal links between cortical excitability and behavioral processing.

In the present study, we show that the FEF is involved at the theta frequency during this attentional search. Previous studies investigating the spontaneous activity of the frontoparietal region (Rosanova et al., 2009), and the role 
of the FEF in attentional search in monkeys (Buschman and Miller, 2007, 2009) and humans (Phillips and Takeda, 2010; Chanes et al., 2013; Quentin et al., 2015), however, showed periodicity in the low (13-24 Hz) and high (36-56 $\mathrm{Hz}$ ) beta frequency range. Given the use of multiple delays in the different TMS studies presented here, frequencies $>10 \mathrm{~Hz}$ could not be characterized. Thus, we cannot rule out that other, higher frequencies are related to attentional sampling during this difficult visual search. It is even possible that the use of $25 \mathrm{~ms}$ TMS double-pulses in two of the three studies (Dugué et al., 2011; and current) could have assisted in recruiting some of these oscillations ( $\sim 40$ $\mathrm{Hz}$ ); the fact that compatible results were obtained in the third study (Dugué et al., 2015a) without this $40 \mathrm{~Hz}$ periodicity, however, indicates that it could be instrumental but not strictly necessary for recording TMS modulations of visual search.

In addition to the theta (VanRullen et al., 2007; Busch and VanRullen, 2010; Landau and Fries, 2012; Fiebelkorn et al., 2013, 2018; VanRullen, 2013; Song et al., 2014; Huang et al., 2015; Landau et al., 2015; Dugué et al., 2015a,b, 2016, 2017; Helfrich et al., 2018) and beta (as discussed in the previous paragraph) oscillations, there is a great amount of evidence for a modulation of alpha oscillations (synchronization/desynchronization) because of spatial allocation of attention (Worden et al., 2000; Sauseng et al., 2005; Thut et al., 2006; Rihs et al., 2007; Jensen and Mazaheri, 2010; Samaha et al., 2016; Brüers and VanRullen, 2018). It is thus plausible that more than one oscillation coexists and interacts during visual attention, and visual search in particular. Studying the interplay between theta, alpha, and beta oscillations in attentional deployment is an exciting question for future research.

In the present study, we investigated the temporal dynamics of V1 and FEF during attentional search, and revealed that both regions are involved periodically at the theta frequency. This study brings convincing, converging evidence, together with multiple studies using various approach including psychophysics, EEG and TMS, and analysis tools, in favor of a theta, intrinsic rhythm as the support of attentional exploration.

\section{References}

Ashbridge E (1997) Temporal aspects of visual search studied by transcranial magnetic stimulation. Neuropsychologia 35:11211131.

Biel AL, Friedrich EVC (2018) Why you should report Bayes factors in your transcranial brain stimulation studies. Front Psychol 9:1125.

Bressler SL, Tang W, Sylvester CM, Shulman GL, Corbetta M (2008) Top-down control of human visual cortex by frontal and parietal cortex in anticipatory visual spatial attention. J Neurosci 28: 10056-10061.

Brüers S, VanRullen R (2018) Alpha power modulates perception independently of endogenous factors. Front Neurosci 12:279.

Busch NA, VanRullen R (2010) Spontaneous EEG oscillations reveal periodic sampling of visual attention. Proc Natl Acad Sci U S A 107:16048-16053.

Buschman TJ, Miller EK (2007) Top-down versus bottom-up control of attention in the prefrontal and posterior parietal cortices. Science 315:1860-1862.

Buschman TJ, Miller EK (2009) Serial, covert shifts of attention during visual search are reflected by the frontal eye fields and correlated with population oscillations. Neuron 63:386-396.
Chanes L, Chica AB, Quentin R, Valero-Cabré A (2012) Manipulation of pre-target activity on the right frontal eye field enhances conscious visual perception in humans. PLoS One 7:e36232.

Chanes L, Quentin R, Tallon-Baudry C, Valero-Cabré A (2013) Causal frequency-specific contributions of frontal spatiotemporal patterns induced by non-invasive neurostimulation to human visual performance. J Neurosci 33:5000-5005.

Corbetta M, Shulman GL (2002) Control of goal-directed and stimulus-driven attention in the brain. Nat Rev Neurosci 3:201215.

Deco G, Pollatos O, Zihl J (2002) The time course of selective visual attention: theory and experiments. Vision Res 42:2925-2945.

Dugué L, Marque P, VanRullen R (2011) Transcranial magnetic stimulation reveals attentional feedback to area $\mathrm{V} 1$ during serial visual search. PLoS One 6:e19712.

Dugué L, Marque P, VanRullen R (2015a) Theta oscillations modulate attentional search performance periodically. J Cogn Neurosci 27: 945-958.

Dugué L, McLelland D, Lajous M, VanRullen R (2015b) Attention searches nonuniformly in space and in time. Proc Natl Acad Sci U S A 112:15214-15219.

Dugué L, Roberts M, Carrasco M (2016) Attention reorients periodically. Curr Biol 26:1595-1601.

Dugué L, VanRullen R (2014) The dynamics of attentional sampling during visual search revealed by Fourier analysis of periodic noise interference. J Vis 14(2):11 1-15.

Dugué L, VanRullen R (2017) Transcranial magnetic stimulation reveals intrinsic perceptual and attentional rhythms. Front Neurosci 11:154.

Dugué L, Xue AM, Carrasco M (2017) Distinct perceptual rhythms for feature and conjunction searches. J Vis 17(3):22 1-15.

Eckstein MP (2011) Visual search: a retrospective. J Vis 11(5):14 1-36.

Ellison A, Lane AR, Schenk T (2007) The interaction of brain regions during visual search processing as revealed by transcranial magnetic stimulation. Cereb Cortex 17:2579-2584.

Ellison A, Schindler I, Pattison LL, Milner AD (2004) An exploration of the role of the superior temporal gyrus in visual search and spatial perception using TMS. Brain 127:2307-2315.

Fiebelkorn IC, Pinsk MA, Kastner S (2018) A dynamic interplay within the frontoparietal network underlies rhythmic spatial attention. Neuron 99:842-853.e8.

Fiebelkorn IC, Saalmann YB, Kastner S (2013) Rhythmic sampling within and between objects despite sustained attention at a cued location. Curr Biol 23:2553-2558.

Fuggetta G, Pavone EF, Walsh V, Kiss M, Eimer M (2006) Corticocortical interactions in spatial attention: a combined ERP/TMS study. J Neurophysiol 95:3277-3280.

Helfrich RF, Fiebelkorn IC, Szczepanski SM, Lin JJ, Parvizi J, Knight RT, Kastner S (2018) Neural mechanisms of sustained attention are rhythmic. Neuron 99:854-865.e5.

Huang Y, Chen L, Luo H (2015) Behavioral oscillation in priming: competing perceptual predictions conveyed in alternating thetaband rhythms. J Neurosci 35:2830-2837.

Itti L, Koch C (2001) Computational modelling of visual attention. Nat Rev Neurosci 2:194-203.

Jensen O, Mazaheri A (2010) Shaping functional architecture by oscillatory alpha activity: gating by inhibition. Front Hum Neurosci 4:186.

Juan CH, Walsh V (2003) Feedback to V1: a reverse hierarchy in vision. Exp Brain Res 150:259-263.

Kalla R, Muggleton NG, Cowey A, Walsh V (2009) Human dorsolateral prefrontal cortex is involved in visual search for conjunctions but not features: a theta TMS study. Cortex 45:1085-1090.

Kalla R, Muggleton NG, Juan CH, Cowey A, Walsh V (2008) The timing of the involvement of the frontal eye fields and posterior parietal cortex in visual search. Neuroreport 19:1067-1071.

Kastner S, Pinsk MA (2004) Visual attention as a multilevel selection process. Cogn Affect Behav Neurosci 4:483-500. 
Kastner S, Pinsk MA, De Weerd P, Desimone R, Ungerleider LG (1999) Increased activity in human visual cortex during directed attention in the absence of visual stimulation. Neuron 22:751-761.

Kienitz R, Schmiedt JT, Shapcott KA, Kouroupaki K, Saunders RC, Schmid MC (2018) Theta rhythmic neuronal activity and reaction times arising from cortical receptive field interactions during distributed attention. Curr Biol 28:2377-2387.e5.

Landau AN, Fries P (2012) Attention samples stimuli rhythmically. Curr Biol 22:1000-1004.

Landau AN, Schreyer HM, van Pelt S, Fries P (2015) Distributed attention is implemented through theta-rhythmic gamma modulation. Curr Biol 25:2332-2337.

Lane AR, Smith DT, Schenk T, Ellison A (2011) The involvement of posterior parietal cortex in feature and conjunction visuomotor search. J Cogn Neurosci 23:1964-1972.

Lopez-Alonso V, Liew SL, Fernández Del Olmo M, Cheeran B, Sandrini M, Abe M, Cohen LG (2018) A preliminary comparison of motor learning across different non-invasive brain stimulation paradigms shows no consistent modulations. Front Neurosci 12:253.

Mehta AD, Ulbert I, Schroeder CE (2000) Intermodal selective attention in monkeys. II: Physiological mechanisms of modulation. Cereb Cortex 10:359-370.

Motter BC (1994) Neural correlates of attentive selection for color or luminance in extrastriate area V4. J Neurosci 14:2178-2189.

Muggleton NG, Cowey A, Walsh V (2008) The role of the angular gyrus in visual conjunction search investigated using signal detection analysis and transcranial magnetic stimulation. Neuropsychologia 46:2198-2202.

Muggleton NG, Juan CH, Cowey A, Walsh V (2003) Human frontal eye fields and visual search. J Neurophysiol 89:3340-3343.

Muggleton NG, Kalla R, Juan CH, Walsh V (2011) Dissociating the contributions of human frontal eye fields and posterior parietal cortex to visual search. J Neurophysiol 105:2891-2896.

Nakayama K, Martini P (2011) Situating visual search. Vision Res 51:1526-1537.

O'Shea J, Muggleton NG, Cowey A, Walsh V (2004) Timing of target discrimination in human frontal eye fields. J Cogn Neurosci 16: 1060-1067.

Palmer J, Ames CT, Lindsey DT (1993) Measuring the effect of attention on simple visual search. J Exp Psychol Hum Percept Perform 19:108-130.

Paus T (1996) Location and function of the human frontal eye-field: a selective review. Neuropsychologia 34:475-483.

Phillips WA (1974) On the distinction between sensory storage and short-term visual memory. Percept Psychophys 16:283-290.

Phillips S, Takeda Y (2010) Frontal-parietal synchrony in elderly EEG for visual search. Int J Psychophysiol 75:39-43.

Quentin R, Chanes L, Vernet M, Valero-Cabré A (2015) Frontoparietal anatomical connections influence the modulation of conscious visual perception by high-beta frontal oscillatory activity. Cereb Cortex 25:2095-2101.

Rihs TA, Michel CM, Thut G (2007) Mechanisms of selective inhibition in visual spatial attention are indexed by alpha-band EEG synchronization. Eur J Neurosci 25:603-610.
Rosanova M, Casali A, Bellina V, Resta F, Mariotti M, Massimini M (2009) Natural frequencies of human corticothalamic circuits. J Neurosci 29:7679-7685.

Saalmann YB, Pigarev IN, Vidyasagar TR (2007) Neural mechanisms of visual attention: how top-down feedback highlights relevant locations. Science 316:1612-1615.

Rossi S, Hallett M, Rossini PM, Pascual-Leone A, Safety of TMS Consensus Group (2009) Safety, ethical considerations, and application guidelines for the use of transcranial magnetic stimulation in clinical practice and research. Clin Neurophysiol 120:20082039.

Samaha J, Sprague TC, Postle BR (2016) Decoding and reconstructing the focus of spatial attention from the topography of alphaband oscillations. J Cogn Neurosci 28:1090-1097.

Sauseng P, Klimesch W, Stadler W, Schabus M, Doppelmayr M, Hanslmayr S, Gruber WR, Birbaumer N (2005) A shift of visual spatial attention is selectively associated with human EEG alpha activity. Eur J Neurosci 22:2917-2926.

Schindler I, Ellison A, Milner AD (2008) Contralateral visual search deficits following TMS. J Neuropsychol 2:501-508.

Schroeder CE, Mehta AD, Foxe JJ (2001) Determinants and mechanisms of attentional modulation of neural processing. Front Biosci 6:D672-D684.

Song K, Meng M, Chen L, Zhou K, Luo H (2014) Behavioral oscillations in attention: rhythmic $\alpha$ pulses mediated through $\theta$ band. $J$ Neurosci 34:4837-4844.

Spyropoulos G, Bosman CA, Fries P (2018) A theta rhythm in macaque visual cortex and its attentional modulation. Proc Natl Acad Sci U S A 115: E5614-E5623.

Thut G, Nietzel A, Brandt SA, Pascual-Leone A (2006) Alpha-band electroencephalographic activity over occipital cortex indexes visuospatial attention bias and predicts visual target detection. $\mathrm{J}$ Neurosci 26:9494-9502.

Treisman A (1998) Feature binding, attention and object perception. Philos Trans R Soc Lond B Biol Sci 353:1295-1306.

van Diepen RM, Miller LM, Mazaheri A, Geng JJ (2016) The role of alpha activity in spatial and feature-based attention. eNeuro 3:ENEURO.0204-16.2016.

VanRullen R (2013) Visual attention: a rhythmic process? Curr Biol 23:R1110-R1112.

VanRullen R (2016) Perceptual cycles. Trends Cogn Sci 20:723735.

VanRullen R, Carlson T, Cavanagh P (2007) The blinking spotlight of attention. Proc Natl Acad Sci U S A 104:19204-19209.

Walsh V, Ashbridge E, Cowey A (1998) Cortical plasticity in perceptual learning demonstrated by transcranial magnetic stimulation. Neuropsychologia 36:363-367.

Worden MS, Foxe JJ, Wang N, Simpson GV (2000) Anticipatory biasing of visuospatial attention indexed by retinotopically specific alpha-band electroencephalography increases over occipital cortex. J Neurosci 20:RC63.

Yan Y, Wei R, Zhang Q, Jin Z, Li L (2016) Differential roles of the dorsal prefrontal and posterior parietal cortices in visual search: a TMS study. Sci Rep 6:30300. 